\title{
Nonmonotone backward masking functions and brightness reversals
}

\author{
Alan L. Stewart • Dean G. Purcell • Roger S. Pinkham
}

Published online: 6 July 2011

(C) Psychonomic Society, Inc. 2011

\begin{abstract}
Increasing the target-field luminance aids detection for a simultaneously presented black target disc and a black masking annulus. At an intermediate interval separating the onset of the target from the mask, increasing the target-field luminance reduces target detection. This decrease in performance occurs with both temporal and spatial forced choice tasks. With a spatial forced choice, an observer's performance can fall below chance. We associate below-chance performance with a brightness reversal of the black target disc, such that the target disc appears brighter than its surround. The occurrence of brightness reversals follows from our model of the Broca-Sulzer effect, and nonmonotone masking functions result from a generalization of luminance summation.
\end{abstract}

Keywords Visual backward masking · U-shaped functions · Broca-Sulzer effect · Brightness reversal . Metacontrast masking

\footnotetext{
A. L. Stewart $(\bowtie) \cdot$ R. S. Pinkham

Stevens Institute of Technology,

Hoboken, NJ, USA

e-mail: alouisstewart@gmail.com

R. S. Pinkham

e-mail: rpinkham@stevens-tech.edu

D. G. Purcell

Oakland University,

Rochester, MI, USA

D. G. Purcell

e-mail: purcell@oakland.edu

A. L. Stewart

28 Meadow Lane,

Little Compton, RI 02837, USA
}

The detection of a briefly flashed target, such as a black disc, is sometimes suppressed by the onset of a second stimulus, the masking stimulus. When the target is followed by a surrounding figure, such as a black annulus, the interplay of target and mask is called backward masking. Under conditions of backward masking, both target detection and letter identification can decrease as the delay between the onset of the stimulus and the onset of the mask increases. The resulting nonmonotone performance curves are addressed by most accounts of visual masking (Breitmeyer \& Öğmen, 2006). Under some conditions, however, target detection is worse than chance. No current explanation of masking accounts for below-chance performance.

Our account of below-chance performance rests on three propositions: (i) A spatial two-alternative forced choice (2AFC) task can produce nonmonotone performance curves. For pronounced nonmonotone curves, detection can be worse than chance. (ii) These nonmonotone backward-masking curves represent a change in an observer's sensitivity for certain delays between target and mask onset, even for targets that fall on the fovea. A dark target, followed by an appropriate masking stimulus, sometimes appears to be brighter than its background, a phenomenon we have called a brightness reversal (Purcell \& Dember, 1968; Stewart, Purcell, \& Dember, 1968). Pronounced brightness reversals occur with black-on-white figures and can lead to below-chance target detection. (iii) Our conjecture is that brightness reversals result from the same combination of excitation, inhibition, and luminance summation that produces the Broca-Sulzer effect (Berman \& Stewart, 1978a, 1978b, 1979; Marks, 1974). These brightness reversals result in below-chance performance with a spatial 2AFC. 


\section{Experiment 1: Below-chance detection}

We produced below-chance detection by allowing an observer to compare two masking figures simultaneously. The target field was a black disc on a white surround, as shown in Fig. 1. The disc was positioned on the left or right side of the stimulus field, and the observer was forced to choose between the two possible locations of the target. The masking field contained two black annuli. The illuminated interior disc of one annulus fell on the same area as the black target disc. The second annulus fell on a uniformly illuminated region of the target field. The independent variable was the time from the onset of the target field to the onset of the mask field (the stimulus onset asynchrony or $S O A$ ). From past experiments, we knew that increasing the luminance of the target background makes it easier to detect the target at $\mathrm{SOA}=0$ while decreasing target detection at an intermediate SOA (Purcell \& Stewart, 1969, 1974; Purcell, Stewart, \& Dember, 1969). Pilot studies revealed that increasing the luminance also produced brightness reversals of the target at some intermediate SOA. That is, at some intermediate SOA, the target disc appeared to be brighter than its field and brighter than the interior disc of the target-absent annulus.

a Timing Sequence

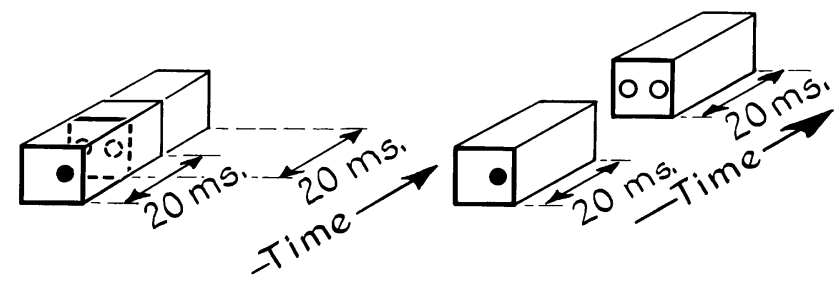

b Target-Mask Configuration
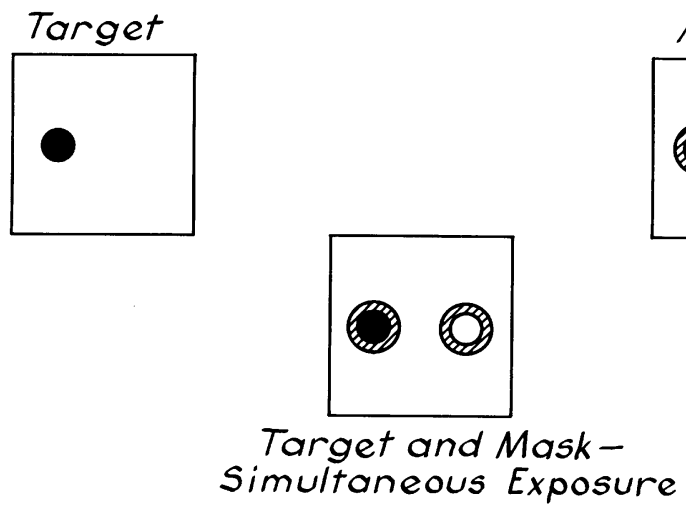

Fig. 1 Stimulus and timing diagram for the spatial two-alternative forced choice experiments
Method

Stimuli The target figure was a black disc subtending $0.4 \mathrm{deg}$ of arc. The mask figure was a black annulus, with an inner diameter of $0.4 \mathrm{deg}$ and a strip width of $0.17 \mathrm{deg}$. The mask field contained two annuli positioned within a 3deg-square illuminated field. When the target and mask fields were exposed simultaneously the target disc fit snugly within one of the annuli. The annuli were separated by $1.5 \mathrm{deg}$, center to center, and oriented to the left and right of the center of the mask field. The dark adaptation field consisted of a single fixation point (a pinpoint of red light). The target and mask stimuli were centered on either side of the fixation point.

We used a three-field tachistoscope (Model GB, Scientific Prototype, New York) to present the stimuli. The same equipment was used in each of the following experiments, as well. Target-field luminance was established by varying the intensity of the tachistoscope's lamps. The background was fixed at $4.8,11.5,18.1$, or $33.5 \mathrm{~cd} \mathrm{~m}^{-2}$ (with corresponding target disc luminance values of $0.22,0.54$, 0.89 , or $1.68 \mathrm{~cd} \mathrm{~m}^{-2}$ ). Both the target and background varied together, resulting in a constant ratio of intensity. We often refer to simultaneous change in the luminance of the target and its surround as a change in the luminance of the target field. The white portion of the mask was constant at $127.3 \mathrm{~cd} \mathrm{~m}^{-2}$, while the corresponding luminance of the annuli was $6.4 \mathrm{~cd} \mathrm{~m}^{-2}$. Previous work had shown that target detection at $\mathrm{SOA}=0$ was poor for the $4.8 \mathrm{~cd} \mathrm{~m}^{-2}$ target field but improved as target luminance increased. We expected that the $4.8 \mathrm{~cd} \mathrm{~m}^{-2}$ target field would produce a monotone-increasing masking function. With each increase in the luminance of the target field, we expected better and better performance at $\mathrm{SOA}=0$. At intermediate asynchronies, we expected pronounced decreases in performance.

Procedure Observers were told that the experiment was designed to study his or her ability to detect a briefly presented target stimulus under difficult viewing conditions. While we have observed brightness-reversed figures under a variety of conditions, including light adaptation, reversals are most obvious under conditions of dark adaptation. Therefore, observers were dark adapted for $20 \mathrm{~min}$ before data collection. They were instructed to look at the fixation point as they initiated each trial with a thumb switch. On each trial, the target disc was positioned so that one of the annuli fell on the area contiguous with the target's perimeter. The observer's task was to determine whether the target disc was located to the left or right of the fixation point, guessing when necessary. No feedback was given.

In this spatial 2AFC experiment, the intertrial interval was never less then $15 \mathrm{~s}$. Preliminary experiments showed that a 15-s intertrial interval was sufficient to maintain 
adequate dark adaptation. Viewing was monocular. Data were gathered for SOAs ranging from 0 to $60 \mathrm{~ms}$, in $10-\mathrm{ms}$ steps. A total of 50 responses were recorded for each observer at each SOA, in blocks of 25 responses. All blocks were randomized.

Observers All observers were well trained and had participated in a number of masking experiments. A total of 5 observers were used ( 2 male and 3 female).

Results

The statistical analysis of such data is simplified if only the descending limb of the nonmonotone function is analyzed (Purcell \& Stewart, 1970, 1974). Previous experiments indicated that the observer's performance decreases over the first three SOAs. Accordingly, only those points were subjected to a repeated measures analysis of variance.

The data represented in Fig. 2 show percent correct detection of the target, averaged across all 5 observers, and they establish that a spatial $2 \mathrm{AFC}$ can result in detection that is significantly below chance, our first proposition. Increasing target-field luminance improves the observer's accuracy at $\mathrm{SOA}=0$, but this relationship reverses as SOA increases through $20 \mathrm{~ms}$ (percent correct detection is at or close to $100 \%$ for SOAs greater than $40 \mathrm{~ms}$, and these data are not plotted). The statistical effect of luminance, $F(3,12)=6.91$, $p<.01, \eta_{\mathrm{p}}^{2}=.63$, and the interaction of luminance with

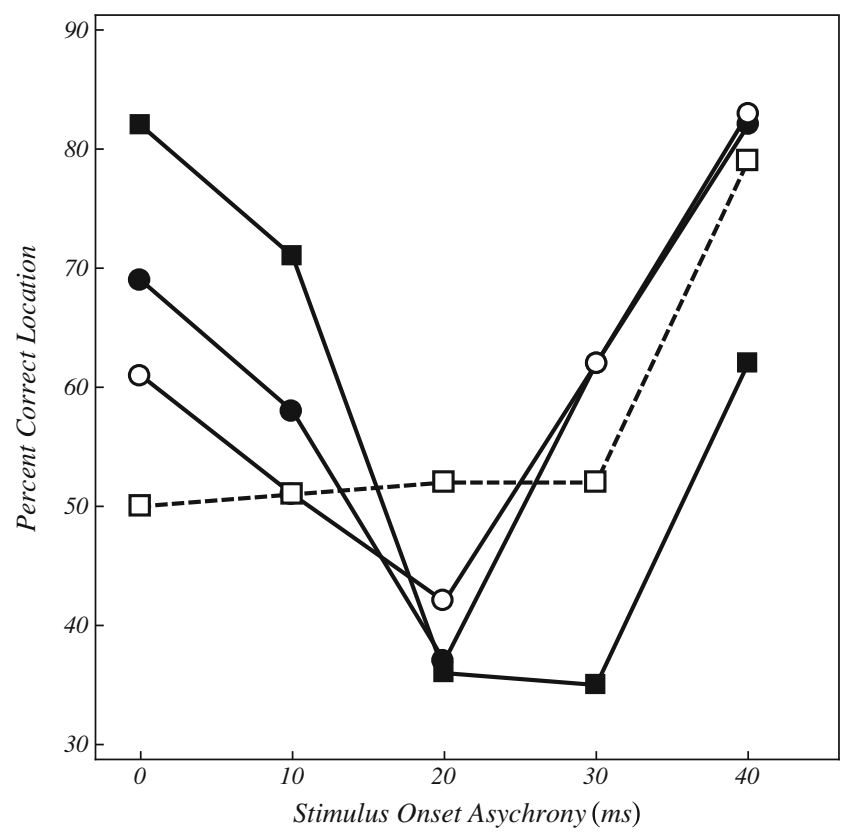

Fig. 2 Target detection when the target field is set at 33.5 (solid squares), 18.1 (solid circles), 11.5 (open circles), or $4.8 \mathrm{~cd} \mathrm{~m}^{-2}$ (open squares). All three nonmonotone performance curves show belowchance performance at $\mathrm{SOA}=20 \mathrm{~ms}$
SOA, $F(6,24)=9.75, p<.001, \eta_{\mathrm{p}}^{2}=.71$, support this interpretation. The main effect of SOA gives $F(2,8)=31.81$, $p<.001, \eta_{\mathrm{p}}{ }^{2}=.89$. The target was always in one of two locations. If an observer had no information about the target and simply guessed as to its location, he or she would be correct on half of the trials. Instead, each observer scored below chance at $\mathrm{SOA}=20 \mathrm{~ms}$, although the U-minimum performance of each observer was at a different SOA. At an observer's performance minimum, and at the highest target luminance, the individual detection values were $46 \%, 42 \%$, $22 \%, 20 \%$, and $12 \%$ correct. We presume that observers completed their task by comparing the interior of the targetpresent masking annulus with the interior of the nearby target-absent masking annulus. At their below-chance minimum, observers often saw the area occupied by the black target as brighter than the interior of the target-absent masking annulus. The black target disc was being brightness reversed by the masking field, causing the observer to mistake the target-absent masking figure for the target's location. Our speculation is that in this form of backward masking both brightness reversals and the Broca-Sulzer effect result from the same interplay of excitation and inhibition (Marks, 1974).

The Broca-Sulzer effect: A second-order effect The BrocaSulzer effect refers to the brightness of a briefly flashed spatially homogeneous patch of light (see Fig 3; Broca \& Sulzer, 1902; Marks, 1974). At high luminance, the brightness of the patch of light increases for flash durations up to $30 \mathrm{~ms}$. For durations longer than $30 \mathrm{~ms}$ but much less than $1 \mathrm{~s}$, brightness decreases. That is, a pulsed light of intermediate duration is brighter than one of lesser or greater duration.

The Broca-Sulzer effect is puzzling. It is produced with brief stimuli that cause a transient visual response that increases rapidly and then decreases almost as quickly. Plotting a transient visual response produces a curve that resembles a Broca-Sulzer curve. Yet, as Wasserman and Kong (1974) made clear, the Broca-Sulzer effect cannot be the result of transient visual activity. In a Broca-Sulzer experiment the observer does not see a patch of light growing and then dimming over time. Instead, the observer sees a bright patch of light of a steady brightness - the brightness does not vary with time, as it would with a transient response, but varies with the duration of the stimulus. To compound the paradox, the Broca-Sulzer effect is sometimes said to be an exception to Bloch's law of luminance summation (Boynton, 1961; Higgins \& Rinalducci, 1975). In the General Discussion, we show how a form of luminance summation maps visual activity, as a function of time, to a brightness function that varies with the duration of the stimulus, offering a solution for the Broca-Sulzer puzzle. 
We believe that the Broca-Sulzer effect and some forms of backward masking are second-order effects. A first-order effect is a visual phenomenon that results from simple excitation - a phenomenon such as spatial summation at threshold in the dark-adapted eye. By a second-order effect, we mean a phenomenon that results from combining excitation with a reactive pattern of inhibition.

All models use the terms target and mask to refer to the stimuli, just as we do. Other models of masking also discuss the effect of the mask on the target. Once a stimulus is labeled as a target or a mask, it is tempting to think of each stimulus as a distinct vehicle instead of a pattern of illumination. Explanations of visual masking often discuss the visual response to the target and mask as if they were separate events. The visual response to the mask is then treated as one event, and the mask-produced activity is subtracted from the visual response to the target, a second distinct event (Breitmeyer, 1984; Breitmeyer \& Öğmen, 2000; Francis, 2000, 2003; Weisstein, 1968; Weisstein, Ozog, \& Szoc, 1975). This may be appropriate for higherorder masking effects. It is easier to understand secondorder effects in backward masking, however, by thinking of the target field and the mask field, for a given SOA, as single, time-varying distributions of light rather than as a disc and an annulus. The combined target and mask fields produce a pattern of excitation that varies with space and time at each point in the visual field. Coincident inhibition modulates this pattern of excitation over time and throughout the visual field. An observer's performance depends on both the task he or she is assigned - a brightness judgment, letter recognition, and so forth-and how inhibition refashions the entire pattern of excitation to render the target more or less visible.

While we believe our model applies to all backwardmasking paradigms, we do not believe that all masking phenomena are second-order effects. An example may clarify our point. Under conditions of visual backward masking, a drawing of an upright face is detected at a shorter SOA than is an inverted face. Both an upright face and an inverted face are essentially the same pattern of illumination. Therefore, in the face detection effect (FDE), the visual system is responding to the face as a unit, not to a pattern of illumination as such (Purcell \& Stewart, 1988, 1991; Rolls, Tovée, Purcell, Stewart, \& Azzopardi, 1994). It follows that the FDE is neither a first-order nor a secondorder effect. Although the FDE is revealed under conditions of visual backward masking, it must result from something besides the simple interplay of excitation and inhibition we model in this article.

Broca-Sulzer effect and masking Treating the target and mask as a single stimulus links the Broca-Sulzer effect to the results of Experiment 1. Consider the stimuli of Fig. 1b, a black target disc on a white field and two black annuli on a white surround. The key to understanding the similarities between backward masking and the Broca-Sulzer effect is to follow what happens in a small region around some point $\mathbf{p}$ in the visual field. For the combined target and mask depicted at the bottom of Fig. 1b, when the target disc and the masking annulus are centered on the same point, we refer to that region as $\mathcal{D}$. Loosely speaking, $\mathcal{D}$ represents the region occupied by the target disc. We refer to this as the target-present region. We designate the region about a point $\mathbf{p}$ as $\tilde{\mathcal{D}}$ when the target disc is absent, leaving a uniformly illuminated patch of light in place of the target, as depicted in the right half of the target-and-mask figure. We refer to this as the nontarget region.

First, fix both the target and mask durations at $20 \mathrm{~ms}$. Now consider two SOA values: $\mathrm{SOA}=0 \mathrm{~ms}$, where the target and mask fields come on and go off simultaneously, and $\mathrm{SOA}=20 \mathrm{~ms}$, where the offset of the target field is followed immediately by the onset of the mask field. Further assume that the target field and the mask field are of the same luminance. These assumptions match a rule of thumb in masking, that nonmonotone performance curves are found when target and mask are of equal energy. We idealize the black target disc and black annuli as reflecting no light.

Combining the black target disc and mask $(\mathrm{SOA}=0)$ results in a stimulus where the luminance of the interior of the annulus is $L$ and the region outside the annulus is $2 L$. The target appears gray. Without the target, the interior of the annulus combines with the target field to reflect a luminance of $2 L$, and the interior of the annulus appears white. The brightnesses of the target and the nontarget are then given by one of the Broca-Sulzer curves in Fig. 3. We are dealing with two luminance values ( $L$ and $2 L$ ). Accordingly, we must consult different Broca-Sulzer curves: one curve for any point at luminance $L$, and another for any luminance $2 L$.

Figure 3 represents five Broca-Sulzer curves, one for each of five different luminance values. Brightness is plotted as a function of the flash duration $\tau$. Say that the brightness of the nontarget region is given by the topmost Broca-Sulzer function of Fig. 3 (luminance $2 L$ and duration $\tau=20$, open disk). For the target region, the luminance is $L$, and the brightness is given by the next-lower Broca-Sulzer curve (black disc). The brightness of the target is less than that of the nontarget, and an observer has little trouble in correctly identifying the black target.

So far the narrative is unexceptional. Consider, however, the case where observer performance deteriorates to below chance with an increase in SOA. When SOA $=20 \mathrm{~ms}$, the target and mask surrounds are no longer superimposed. Both the target and the mask surrounds reflect the same luminance $L$ for the full $40 \mathrm{~ms}$, but the target region is illuminated only 


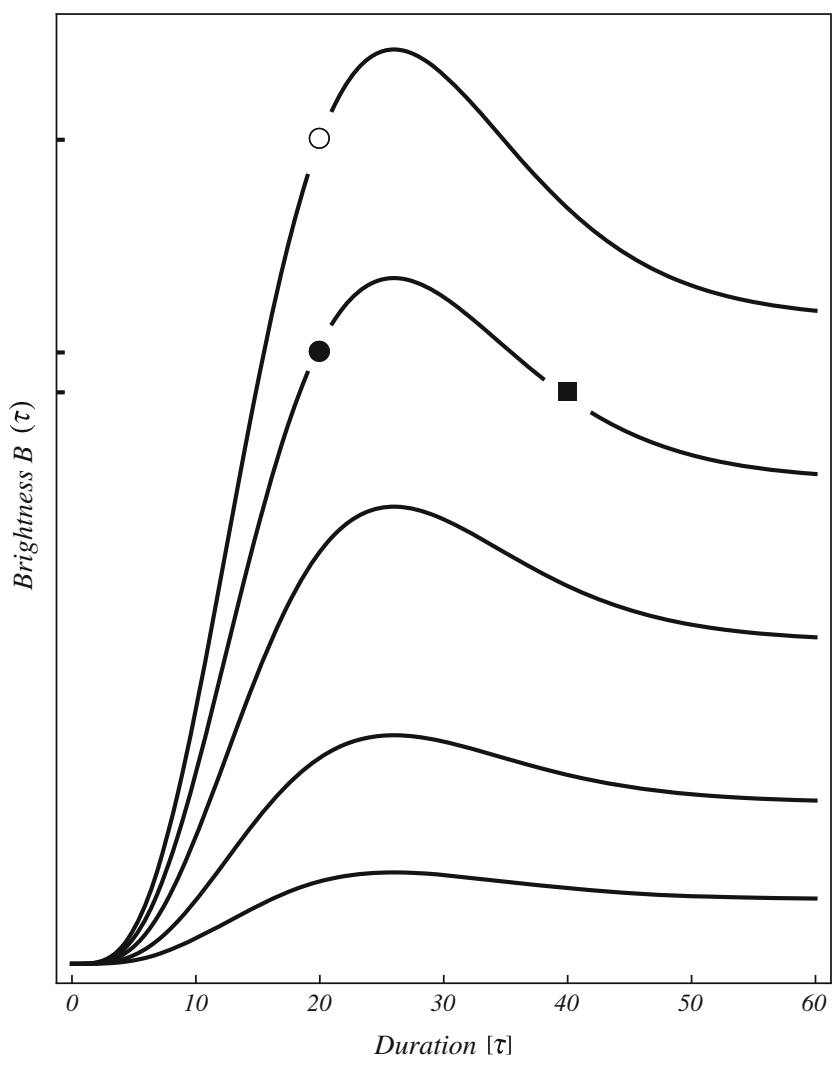

Fig. 3 A family of Broca-Sulzer curves. Each curve represents a different target luminance. Two points represent brightness at a duration of $20 \mathrm{~ms}$. The brighter value is on the Broca-Sulzer curve for a luminance of $2 L$, and the less bright value is on the Broca-Sulzer curve for a luminance $L$. The third point represents the brightness for a stimulus of duration $40 \mathrm{~ms}$ and luminance $L$. The curves were computed using the model outlined in the General Discussion and the Appendix, and they are similar to the curves given in Marks (1974). The model's parameters are listed in Table 1. The same values were used in modeling the descending backward-masking curves of Experiment 1 in Fig. 8

during the $20 \mathrm{~ms}$ when the mask field is present. When the target disc is present, the target area is illuminated at an intensity of $L$ for $20 \mathrm{~ms}$. When the target is absent, the nontarget area is illuminated at an intensity $L$ for $40 \mathrm{~ms}$. The brightnesses of the target and nontarget regions are now given by the same Broca-Sulzer curve: the target at a duration of $20 \mathrm{~ms}$ (black disc), and the nontarget at a duration of $40 \mathrm{~ms}$ (black square). The target-present area is brighter than the target-absent area. If the target is not noticeably different from the nontarget region, then detection will fall to chance, and a nonmonotone masking curve results. If the target is distinguishably brighter than the nontarget, and if an observer is looking for a black target disc, he or she will choose the nontarget over the target area as the location of the target, and the probability of a correct detection will fall below chance, just as we found in Experiment 1.

This narrative, combining the Broca-Sulzer effect with backward masking, is easily extended to brightness rever- sals. Consider a single black disc on a white field of 20-ms duration. Under our simplifying assumption, the region occupied by the black disc is not illuminated until the illuminated mask field is turned on. The area of the black disc is then illuminated for the $20 \mathrm{~ms}$ of the mask exposure. However, the surrounding region is illuminated for $40 \mathrm{~ms}$. The same argument we used to account for backward masking leads to the conclusion that the area occupied by the disc, illuminated for $20 \mathrm{~ms}$, will appear brighter than its surround, illuminated for $40 \mathrm{~ms}$. That is, a brightness reversal occurs when a black disc appears to be brighter than its surround under conditions of visual backward masking.

\section{Experiment 2: Foveal and parafoveal sensitivity $\left(d^{\prime}\right)$}

Given the below-chance performance of each of our observers in Experiment 1, we are left with the question of why below-chance performance is not more widely noted? The difference between a target-absent area and the brightness-reversed target-present area is small. Belowchance detection may occur only when the target and the nontarget are compared side by side, as in Experiment 1 .

We designed a signal detection experiment to test this possibility, using the stimuli of Experiment 1 . In a signal detection experiment, an observer with no information about a target has a false-positive rate equal to the hit rate (the dashed lines in Fig. 4). Below-chance performance has a hit rate less than the false-positive rate. Accordingly, below-chance performance is indicated by a receiver operating characteristic (ROC) with hit rates less than the false-positive rates (Waldmann \& Göttert, 1989). A signal detection experiment also provides a further test of our first proposition, that nonmonotone detection functions represent a decrease in an observer's sensitivity.

Nonmonotone backward-masking functions are an accepted fact (Francis, 2000; Stewart \& Purcell, 1970; Weisstein \& Haber, 1965). Nonetheless, dealing with an unusual finding such as below-chance performance calls for caution. Nonmonotone masking functions might not reflect nonmonotone changes in sensitivity, and it is possible that sufficient practice might eliminate the masking (Bernstein, Proctor, Proctor, \& Schurman, 1973; Hogben \& Di Lollo, 1984; Schwiedrzik, Singer, \& Melloni, 2009; Ventura, 1980; Wolford, Marchak, \& Hughes, 1988). We used extensive training to eliminate practice effects and a rating procedure to estimate each observer's sensitivity as measured by his ROC. We also used many stimulus trials, to ensure that changes in performance represented changes in an observer's sensitivity. 

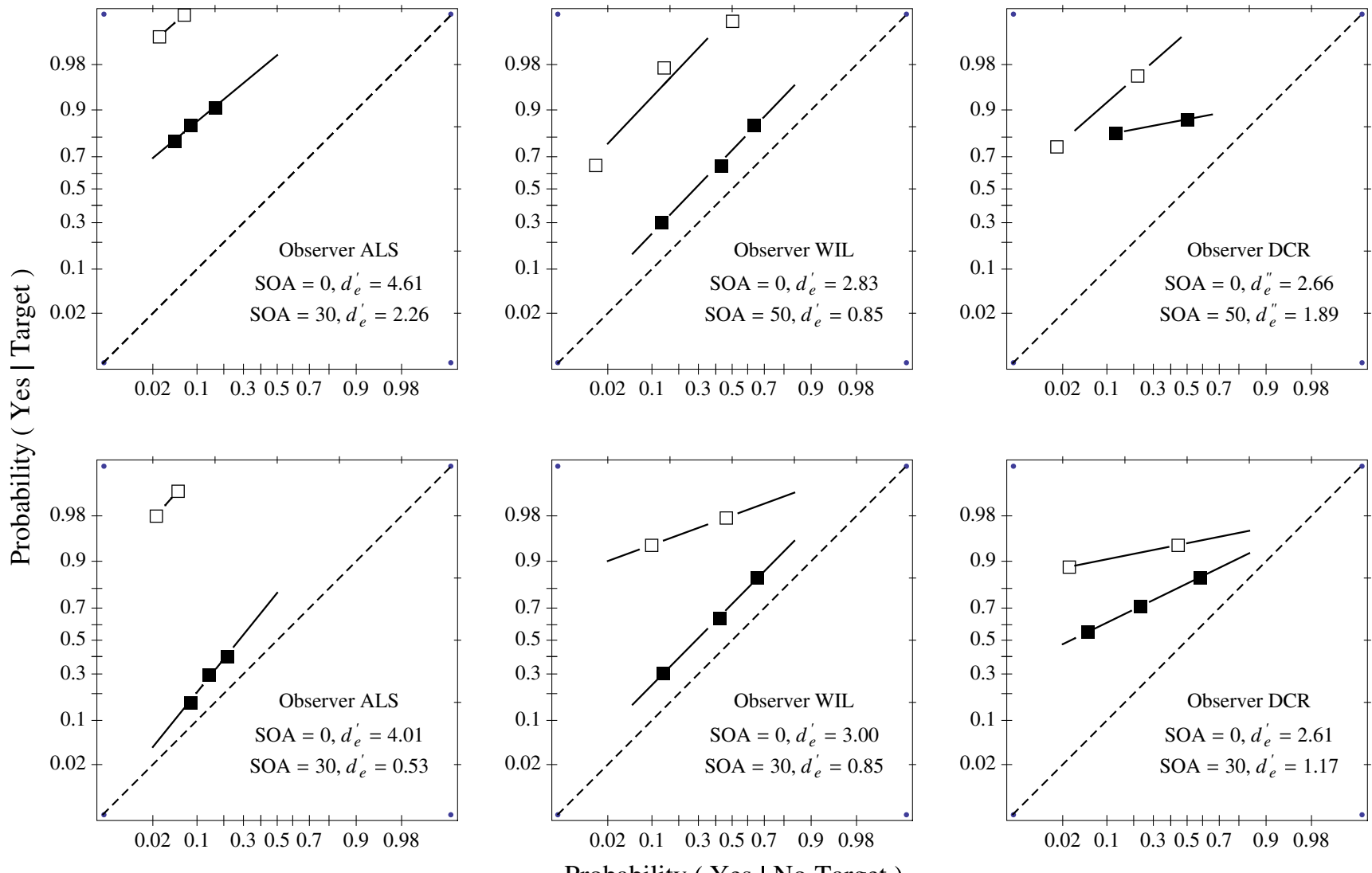

Fig. 4 ROC plots for foveal (top panels) and parafoveal (bottom panels) backward masking (Experiment 2). The open squares represents detection at $\mathrm{SOA}=0$, and the black squares represent detection with the SOA associated with each observer's below-chance

\section{Method}

The Broca-Sulzer effect is most pronounced for a parafoveal target (Corwin, 1978; Osaka, 1982). Likewise, backward masking is stronger in the parafovea than in the fovea (Breitmeyer \& Öğmen, 2006, p. 199). To compare performance in both the fovea and the parafovea, we ran two masking experiments. One experiment used stimuli presented to the fovea, and the second experiment used stimuli presented to the parafovea.

Stimuli The target disc and the single masking annulus were the same size as those of Experiment 1. The background luminances of the target-present field and the target-absent field were constant at $63.7 \mathrm{~cd} \mathrm{~m}^{-2}$, while the black target disc reflected a luminance of $3.2 \mathrm{~cd} \mathrm{~m}^{-2}$. The luminances of the mask field and its interior disc were constant at $127 \mathrm{~cd} \mathrm{~m}^{-2}$, while its black annulus reflected a luminance of $6.4 \mathrm{~cd} \mathrm{~m}^{-2}$. The target-present, target-absent, and mask-field durations were constant at $20 \mathrm{~ms}$. The interval between trials was dark and was at least $15 \mathrm{~s}$ long, helping to ensure that each trial was treated as an performance. Each data point represents the probability of correctly detecting a target given the probability of an observer making a falsepositive report

independent event. The target was present on half of the trials according to a random schedule. Each observer was presented 600 trials at each SOA.

Procedure A target trial (the signal trial) consisted of a black disc paired with a black annulus. For the no-target trial (the noise trial), the black disc was replaced by a target-absent field paired with a black annulus. After each individual trial, observers were required to rate their certainty that a target was present. Observers were given a four-category rating scale, ranging from very certain the target was present to not at all certain the target was present. No feedback was given. According to signal detection theory, each category corresponds to one of the observer's simultaneously maintained response criteria, with 1 (very certain) representing a conservative criterion and 4 (not certain) representing a liberal criterion. Following the theory's interpretation of rating scales, we combined responses (hits with hits and false positives with false positives) in each category with those in the next lower category to estimate the hit-to-false-positive ratio associated with the next most liberal criterion (Dorfman \& Alf, 1969; 
Macmillan \& Creelman, 2005). The hits and false positives in the more conservative category are cumulatively added to each successively more liberal category to describe the ROC points plotted in Fig. 4. Because the most liberal criterion accumulates all of the hits and all of the false positives, a four-category rating scale has only three degrees of freedom. As a result, only three points on the ROC curve are completely free to vary with a four-criterion rating scale, and hence only three points are plotted in the figure. In practice, under the easy detection conditions, such as $\mathrm{SOA}=0$, observers used only the most certain ratings, allowing only two ROC points to be estimated.

For foveal backward masking, the stimuli were presented at the point of fixation, located in the center of a fixation figure. The fixation figure consisted of four red pinpoints of light, arranged in a diamond pattern, in an otherwise dark adaptation field. Each point of light was located $0.6 \mathrm{deg}$ from the center of the fixation field. The target was the black disc of Fig. 1, but shifted to the center of the fixation field. The mask was presented as if the right-hand annulus of Fig. 1 was eliminated and the left-hand annulus was shifted to the center of the fixation field.

For parafoveal backward masking, the diamond-shaped fixation pattern was replaced by a single red point of light. The observers fixated on that point at the center of the fixation field. A single target and annulus were positioned $0.7 \mathrm{deg}$ to the left of the point of fixation. As a consequence, the parafoveal stimuli were configured exactly as if the right-hand mask in Fig. 1 had been eliminated.

Previous experiments showed that the U-minima differed from observer to observer. Each observer's U-minimum was assessed as part of the pretest training sessions. His masking function was mapped in 5-ms steps, and an SOA close to his U-minimum performance was selected. Two SOA values were examined: $\mathrm{SOA}=0$ and the $\mathrm{SOA}$ for an observer's U-minimum performance. The ROC was obtained by deriving the maximum likelihood estimate of $\Delta m$ (the difference between the means of distributions of unequal variance) and $s$ (the slope of the ROC curve). The ROC curve of each observer is plotted in normal-deviate coordinates in Fig. 4.

Observers were dark adapted for $20 \mathrm{~min}$ before data collection. Viewing was monocular, and observers initiated each trial with a thumb switch. On a target trial, the targetpresent field and the masking field were presented at an appropriate SOA. On a no-target trial, the target-absent field and the masking field were presented at an appropriate SOA. Each session began by showing the observer two target and two no-target trials.

Observers All observers were male, and each was given at least $10 \mathrm{~h}$ of training with the experimental procedures to eliminate practice effects. The SOA for an observer's Uminimum performance ranged from $\mathrm{SOA}=30 \mathrm{~ms}$ to $\mathrm{SOA}=$ $50 \mathrm{~ms}$. A group of 3 observers were used, including one of the authors (A.L.S.). Observers W.I.L. and D.C.R. were told that the experiment was designed to study target detection under difficult viewing conditions.

Results and discussion

A glance at Fig. 4 reveals large decreases in sensitivity for all observers as the SOA changes from 0 to the U-minimum performance SOA, just as the experiment was designed to confirm. A second comparison concerns the U-minimum $d_{e}^{\prime}$ values for the fovea and parafovea. The differences are 1.73 for A.L.S. and 0.72 D.C.R. (there was no difference in sensitivity for W.I.L.). Presumably, for 2 observers, the target was more often seen as brighter than the nontarget when the target and mask were presented to the parafovea, causing the observer to misidentify the target. The fact that the target disc was more often seen as brighter in the parafovea than in the fovea is consistent with our conjecture that visual masking and the Broca-Sulzer effect are related, and with Corwin's observation that the Broca-Sulzer effect is most pronounced in the parafovea (Corwin, 1978).

In a signal detection experiment, below-chance performance results in a ROC that plots below the chance diagonal. Yet here, no observer performed worse than chance. Similar parameters had produced below-chance performance in Experiment 1, suggesting that below-chance performance may result only from spatial forced choice tasks. When target and nontarget are separated in time by $10 \mathrm{~s}$ or more, an observer's memory for brightness may not be good enough to distinguish between small differences, an idea we pursued further in the following two experiments.

\section{Experiment 3: Temporal versus spatial detection}

Brightness reversal is an extreme example of how a visual response to the target can change in unexpected ways under conditions of masking. For the sake of discussion, assume that the target and mask illumination and duration are set to produce a brightness reversal. Altering the SOA can then produce one of three distinct visual states. At one end of the continuum of responses, with a short SOA and a highly illuminated surround, the black target appears far darker than its surround. As SOA increases, the target ranges from black to gray and represents the first state of masking (Blanc-Garin, 1969). At a certain point, increases in SOA produce a transition at which the target figure becomes just as bright as its surround and is no longer discriminable 
from it. This is a second visual state of masking, complete masking. This transition to zero perceived contrast occurs at the SOA value where observer performance first drops to chance.

Brightness reversals represent a third state that can result from an interaction between a target and a masking stimulus. Its phenomenal representation can range from a target only slightly brighter than its background to one noticeably brighter than its background (Brussell, Stober, \& Favreau, 1978; Purcell \& Dember, 1968; Stewart et al., 1968). Although brightness reversals might have taken place in our signal detection experiments, they went unnoticed by the observers.

We studied performance at three special SOA values to test this supposition, producing each of the three possible masking states: $\mathrm{SOA}=0$, where the black target appeared as dark gray; the SOA where observer performance first dropped to chance; and the U-minimum SOA, where observer performance was well below chance. These SOA values differed across observers and were determined in preliminary experiments. We designed the experiment to compare a spatial and a temporal forced choice task. The spatial 2AFC was the same task as in Experiment 1, illustrated in Fig. 1. In the temporal 2AFC, the target and mask were those used in the parafoveal condition of Experiment 2.

\section{Method}

Two observers from Experiment 2 were used in Experiment 3 (W.I.L. and D.C.R.). Two additional, well-trained observers were used, neither of whom had participated in the previous masking experiments. All observers were naive as to the purpose of the experiment. The dimensions of the target disc and mask annulus were identical with those of Experiment 1, and viewing was monocular. Target-field luminance was constant at $63.7 \mathrm{~cd} \mathrm{~m}^{-2}$ and mask-field luminance at $127 \mathrm{~cd} \mathrm{~m}^{-2}$. The target and mask durations were constant at $20 \mathrm{~ms}$, and a 15-s intertrial interval separated stimulus presentations. When the spatial $2 \mathrm{AFC}$ was run, the observer made a decision as to the location of the target after each presentation of target and mask. With the temporal $2 \mathrm{AFC}$, the stimulus configuration was the same as in the parafoveal signal detection experiment. The target and mask, and the nontarget field and mask, were presented to the same parafoveal point, located $0.7 \mathrm{deg}$ to the left of the centrally located fixation point. Each trial consisted of two successive presentations: one with target present and one without a target. These presentations were separated from each other in time by $15 \mathrm{~s}$. The target was placed in the first or the second temporal presentation at random. The observer knew that the target was present on only one of the presentations, and that task was to identify whether the target disc was present in the first or the second presentation. Observers were run first in the spatial $2 \mathrm{AFC}$ condition and then in the temporal $2 \mathrm{AFC}$ condition. Observers made a total of 50 observations for each SOA and were run in randomized blocks of 25 observations. Observers used a thumb switch to initiate each trial. No feedback was given.

Such a temporal procedure does give the observer a comparison standard. He knows that the target is present on one of the two stimulus presentations and has only to pick the one on which the center of the masking figure appears darker. If the inability to notice a brightness reversal is the result of imprecise memory of a target's brightness we hypothesized that the 15 -s intertrial interval would be long enough to prevent an effective comparison between the target and no-target conditions.

\section{Results and discussion}

Observer performance deteriorated as SOA increased, as shown in Fig. 5. Statistical analysis showed that the main effect of increasing SOA resulted in $F(2,6)=17.63, p<$ $.005, \eta_{\mathrm{p}}{ }^{2}=.85$, confirming the presence of the decreasing limb of a nonmonotone masking function. There was no statistically significant difference between the forced choice tasks, $F(1,3)=7.09, p=.076, \eta_{\mathrm{p}}{ }^{2}=.70$. As expected, there was a statistically significant interaction of SOA by forced choice task, $F(2,6)=5.81, p<.05, \eta_{\mathrm{p}}{ }^{2}=.66$.

Figure 5 shows that this interaction results from the divergence of the masking functions at the third SOA,

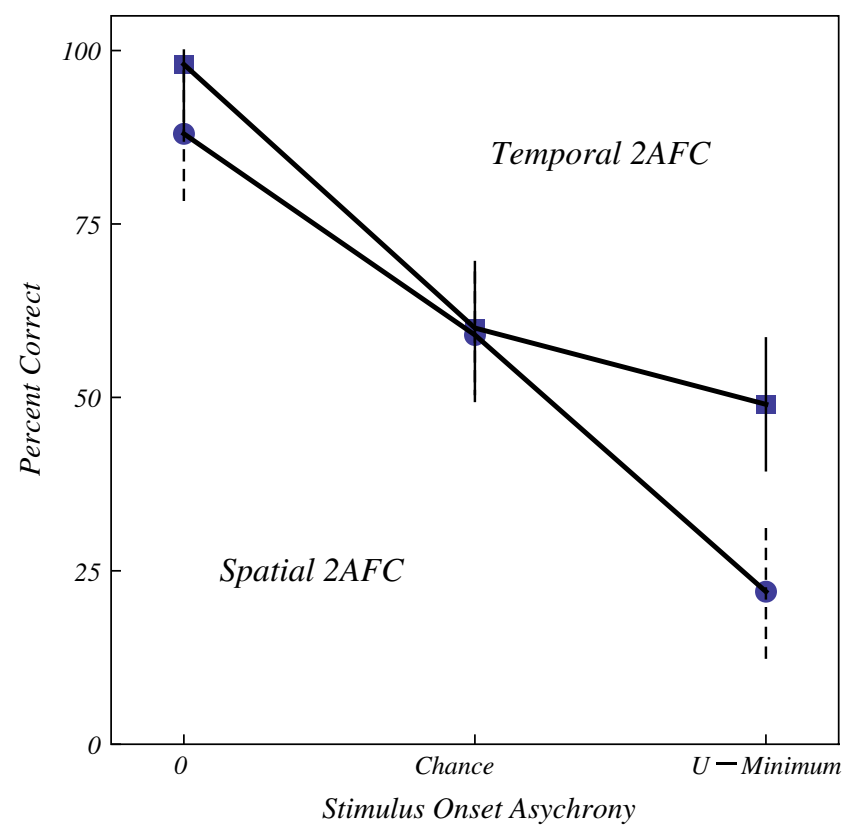

Fig. 5 Temporal versus spatial two-alternative forced choice trials (Experiment 3). The error bars represent 95\% confidence intervals (Jarmasz \& Hollands, 2009) 
where the spatial forced choice results in below-chance performance. It was at this SOA value that we believed brightness reversals had occurred, and, as predicted, the spatial forced choice procedure elicited below-chance detection, whereas the temporal forced choice produced scores at chance. In short, the fading memory for the target's brightness appears to be a critical factor in determining whether performance will drop below chance.

Almost all disc-annulus backward-masking studies have forced observers to make absolute judgments about the target's brightness. These data show how difficult such judgments are, and how unlikely it is that anything other than a direct comparison will result in below-chance performance, even when pronounced brightness reversals occur. It seems that when brightness reversals are present, they can go unnoticed in most masking paradigms, and when they are noticed they are often treated as anomalies (Heckenmuller \& Dember, 1965).

\section{Experiment 4: Spatial forced choice with knowledge of performance}

If brightness reversals lead to below-chance performance, then coaching should improve an observer's performance at a below-chance SOA (Bowen, 1984). We tested this idea by explaining to each observer what a brightness reversal is. We looked for improvement in an observer's ability to locate the black target disc as a result of being informed about his or her performance after each response. We used the target and mask array from Experiment 1, now with two SOA values. First, we selected one SOA at which an observer's performance first fell close to chance (the second state in backward masking). We hypothesized that at this SOA the target disc brightness was close to that of the surround, so knowledge about performance could do little to improve performance. We paired this SOA with one at which the observer's performance was substantially below chance; here, target detection should improve with knowledge about his or her performance as the observer became familiar with a brightness-reversed target.

Method

The experiment was conducted in two stages. In the first stage (no feedback), each observer was run at both the chance and the U-minimum SOA values without information about his or her performance, and before they were told about brightness reversals. This condition replicated two of the pivotal features of the spatial 2AFC task of Experiment 1. In the second stage (feedback), observers were told about brightness reversals and shown a brightness reversal of the disc target produced by a homogeneously illuminated masking field. Each observer was told that a similar reversal of the target might occur with some backwardmasking conditions. Each was left free to discover which condition might produce a reversal of target brightness. Unlike in the no-feedback stage, all observers were given training at both chance and U-minimum SOA values and were told whether each response was correct or incorrect; at least $1 \mathrm{~h}$ of training was given at each SOA, and additional training was given if he or she was still uncomfortable with the task.

The stimulus conditions were identical to those of Experiment 1. Four observers were used. All observers had participated in at least two of the previous experiments. A total of 50 trials were run for each observer at each SOA, for both the no-feedback and the feedback conditions. SOAs were counterbalanced. A 15 -s intertrial interval was used. Throughout the feedback condition, observers were told the target's location after each response (no other experiments had included feedback). Observers used a thumb switch to initiate each trial.

\section{Results and discussion}

Feedback produced an obvious effect at the longest SOA, as can be seen in Fig. 6. There was a statistically significant main effect of feedback, $F(1,3)=122.67, p<.001, \eta_{\mathrm{p}}{ }^{2}=$ .98 , but no statistically significant main effect of SOA, $F(1,3)=0.86$, just as Fig. 6 would lead one to expect. The interaction of SOA by feedback was statistically significant,

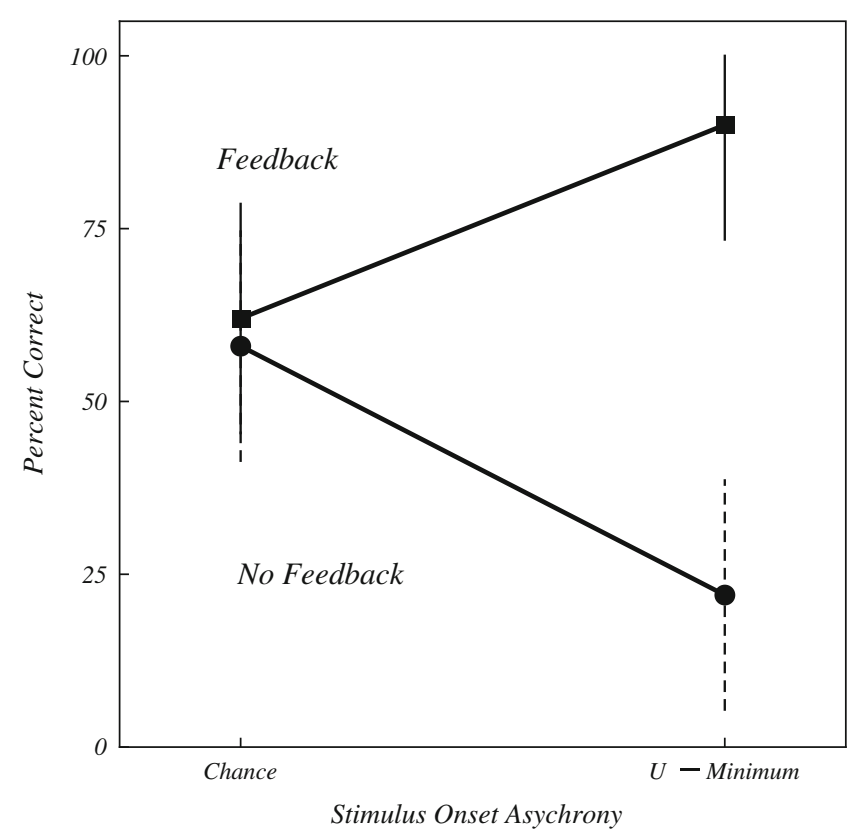

Fig. 6 Backward masking with no feedback and then with feedback after each response (Experiment 4). The error bars represent 95\% confidence intervals 
$F(1,3)=37.74, p<.01, \eta_{\mathrm{p}}{ }^{2}=.93$, as would be expected if feedback made observers aware of brightness reversals.

Figure 6 makes clear that the effect of feedback is slight for SOA values at which the performance of a well-trained observer first falls to chance. Therefore, observer performance along the descending limb of a nonmonotone masking function initially reflects the successive degradation of the target's visual representation. At longer SOA values, where brightness reversals sometimes occur, observer performance must be evaluated more carefully. Under some conditions, brightness reversal of the target can decrease observer performance as effectively as if the target had disappeared. Yet, as Experiment 4 demonstrates, once an observer is given a reference standard and told what a brightness reversal of the target is, he or she can locate this new representation just as successfully as a nonreversed target. However, at an SOA between zero and the SOA that produces a brightness reversal, the target's brightness is indistinguishable from its background, performance is at chance, and coaching does little to improve performance. This represents the second state of visual masking.

\section{General discussion}

\section{A formal model}

Clearly, backward masking involves more than brightness reversals and is more complex than the Broca-Sulzer effect. Unlike the Broca-Sulzer effect, in backward masking we contend with a target figure, a masking figure, the luminance of the target field, the luminance of the mask field, and how the target and mask vary with time. Even so, Experiment 1 is an especially simple example of backward masking. Because an observer's task requires only a brightness judgment, the model we used to compute the Broca-Sulzer curves of Fig. 3 also yields the decreasing limb of the masking functions given in Figs. 2 and 8. When applied to the stimuli and task of Experiment 1, our general mathematical model for backward masking shares the same three equations that model the Broca-Sulzer effect, consistent with our third proposition, that the Broca-Sulzer effect and backward masking are caused by the same interplay of excitation and inhibition. Excitation is given by an operator that produces an excitatory response $r$. Given $r$, the net output $n$ is determined by an equation that represents the sum total of inhibition. Brightness results from a weighted integration of $n$, a generalization of luminance summation. The following is a formal sketch of these three operations.

Excitation Our account of backward masking is a psychophysical theory for mapping luminance into brightness. The first-order response is given by a standard model for excitation (Watson, 1986; a more general, space-variant model is discussed in Stewart, Pinkham, Bittner, \& Purcell, 2003; Stewart, Pinkham, Mancino, \& Chomak, 1999). The model's impulse response is represented by the Gamma density function

$g(t)=t^{k^{-1}} \frac{e^{-t / \sigma}}{\sigma^{k} \Gamma(k)}$,

where $g=0$ for $t \leq 0, k=2$, and $\sigma=\sigma_{r}=4.94\left(\sigma_{r}\right.$ is given in Watson, 1986). The excitatory response $r$ results from convolving the stimulus $f(t)$ with the impulse function,

$r(t)=c \int_{0}^{t} g(t-s) f(s) d s$.

Inhibition The second-order effect of inhibition is modeled by an operator equation

$r=n+F n$.

The operator $F$ is an integral operator (details are given in the Appendix and in Berman \& Stewart, 1978a, 1978b, 1979). A special case is the time-invariant integral equation

$r(t)=n(t)+\lambda \int_{0}^{t} T(t-s) n(s) d s$.

This integral equation is solved easily when $T$ is a Gamma density function. The solution's resolvent kernel $R$ is given in the Appendix, and the solution of Equation (4) has the form

$n(t)=r(t)-\lambda \int_{0}^{t} R(t-s) r(t) d s$.

The impedance equation results from a combination of psychological and mathematical assumptions but does not directly incorporate physiological termshence, the term impedance, used to distinguish our equation from physiological models of inhibition such as the Hartline-Ratliff equation. Both the visual response $r$ and the net output $n$ are functions of time $t$. This contrasts with well-known explanations of nonmonotone masking functions, which posit that inhibition onsets more quickly than excitation (Breitmeyer \& Öğmen, 2000; Weisstein, 1968; see also the discussion of mask blocking by Francis, 2000). Inhibition is a function of excitation for our model, but the buildup of inhibition lags the buildup of excitation and accounts for nonmonotone masking functions.

Brightness A weighted integration of $n(t)$ gives brightness as a function of duration $\tau$ (Berman \& Stewart, 1978a, 
1978b, 1979). For a light pulse of duration $\tau$, brightness is a weighted function of the net output,

$B(\tau)=\int_{0}^{t} n(t) w(\tau, t) d t$

If the net output is constant and the weight $w(\tau, t)=1$, the integral of Equation (6) gives Bloch's law. The BrocaSulzer functions in Fig. 7 were calculated using a weighted average of $n$ for durations $t=\tau$.

$B(\tau)=\int_{0}^{t} n(t) w(\tau-t) d t$.

The weight function $w$ is the Gamma density in Equation (1), with $\sigma_{r}$ replaced by $\sigma_{w}=6.18 \mathrm{~ms}$ (Bowen, 1984; Watson, 1986). Note that the net output $n$ is a function of time, while the Broca-Sulzer function represents brightness that changes with duration $\tau$ (Berman \& Stewart, 1978a, 1978b, 1979; Wasserman \& Kong, 1974).

Below-chance performance

We are now able to explain the nonmonotone masking curves of Experiment 1. We assume that a nonmonotone

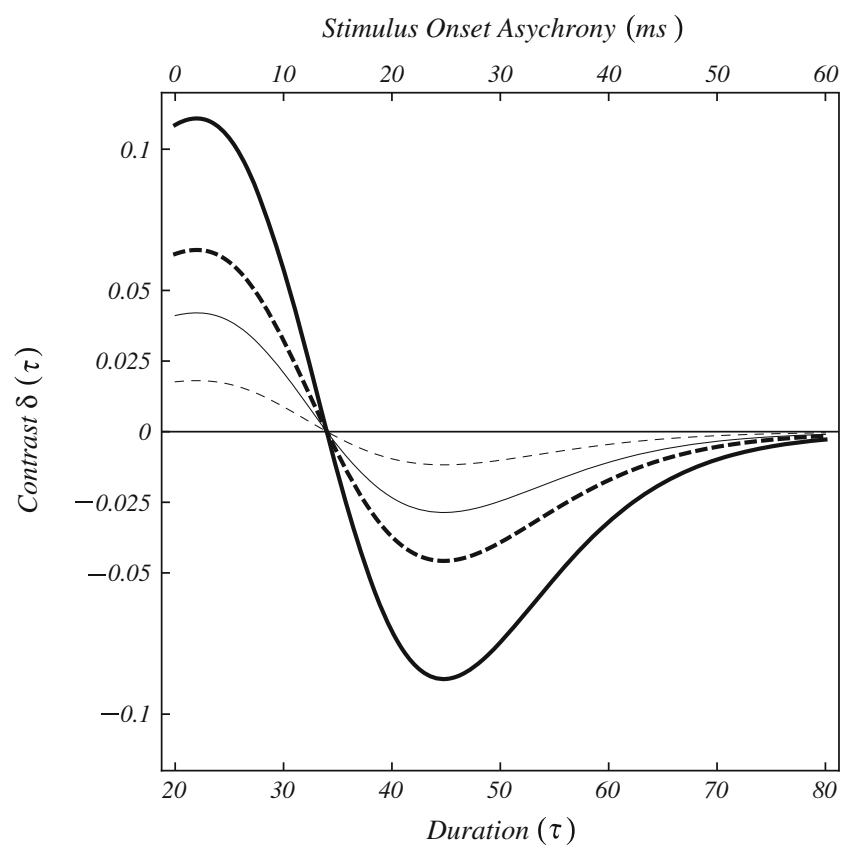

Fig. 7 Visual contrast functions $\delta(\tau)$ for stimulus durations $\tau=\mathrm{SOA}+$ mask duration. The topmost function represents the contrast for the $33.5 \mathrm{~cd} \mathrm{~m}^{-2}$ target-field condition of Experiment 1. The remaining three contrast functions represent the $18.1,11.5$, and $4.8 \mathrm{~cd} \mathrm{~m}^{-2}$ targetfield conditions. Note that $\delta(\tau)$ is near its maximum for the duration $20 \mathrm{~ms}(\mathrm{SOA}=0)$, and $\delta(\tau)$ is at its minimum between durations of 40 and $50 \mathrm{~ms}$ (SOAs of 20 and $30 \mathrm{~ms}$ ), the U-minimum performance level of the backward-masking curves of Fig. 1 masking curve is produced by an interplay of two factors. The initial decrease in performance with an increase in SOA is an elaboration of our account of the Broca-Sulzer effect. At some SOA, the black target appears as bright as the interior of the nontarget masking ring, causing the observer's performance to fall to chance. In the most distinctive case, for an SOA at which the target is brightness reversed, the observer chooses the nontarget area over the target area, causing performance to drop below chance. With increases in SOA, a second factor comes into play. The observer is allowed a longer look at the target, free of any influence of the mask. For a sufficiently long SOA, an observer is able to detect the target before the onset of the mask, and performance improves rapidly.

Our explanation of backward masking accounts for an observer's performance up to the SOA at which an observer has a mask-free glimpse of the target. For the moment, assume that we can calculate the net visual response $n(t)$ associated with the target and nontarget conditions. We outline this calculation in the Appendix. Equation (7) allows us to assign a number $B(\tau)$ to the target area, and to the nontarget area once we know $n(t)$. As a result, we can assign a visual contrast for each masking sequence of duration $\tau$,

$\delta(\tau)=\frac{B(\tau) \text { for } \tilde{\mathcal{D}}-B(\tau) \text { for } \mathcal{D}}{B(\tau) \text { for } \tilde{\mathcal{D}}+B(\tau) \text { for } \mathcal{D}}$.

Even better, we can calculate the contrast for every duration of target SOA plus mask for each of the target and mask luminance conditions of Experiment 1. Figure 7 shows the results of these calculations.

Positive values of $\delta(\tau)$ indicate that the nontarget region $\mathcal{D}$ has a larger value than the black target region $\mathcal{D}$ This portion of the $\delta(\tau)$ function represents the first visual masking state, where that target is more or less gray, depending on its visual contrast, and matches the observer's expectation that the target will appear to be less bright than the nontarget region $\tilde{\mathcal{D}}$. The greater the difference, the more likely it is that an observer will correctly locate the target. Values of $\delta(\tau)$ close to zero represent the second masking state, where an observer can no longer differentiate the target from its surround. The third masking state is represented by negative values of $\delta(\tau)$. Negative values indicate that the black target region has a larger value that the nontarget region, causing an observer to mislocate the target. Negative values of $\delta(\tau)$ are therefore associated with below-chance performance. Recall that the two masking rings are present throughout the duration of the mask, and they are the last thing an observer sees at the offset of the mask. For large SOAs, the net output $n(t)$ for both the target and nontarget areas within the annuli converge to the same value. As a result, 
the contrast falls to zero for long durations (long SOA), as it does in Fig. 7. By that time, however, an observer has already read out the target.

Our supposition is that an observer's detection performance is proportional to the contrast $\delta(\tau)$, so percent correct target location should have the form

$\Delta(\tau)=M \delta(\tau)+m$,

with scaling constants $M$ and $m$. Scaled functions are plotted in Fig. 8 along with the data of Experiment 1. The theoretical $\Delta(\tau)$ functions fit the descending limb of the masking curves well, as shown in Fig. 8. Our attempt to understand the ascending limb begins with the target field $=4.8 \mathrm{~cd} \mathrm{~m}^{-2}$ condition, shown in the lower right graph, where the mask is two orders of magnitude greater than the target. As expected with such an intense mask and with such a small difference between the target and its field luminance, performance is at chance up to $\mathrm{SOA}=30 \mathrm{~ms}$. At $\mathrm{SOA}=$ $40 \mathrm{~ms}$, performance jumps to $80 \%$ correct, indicating that the observer often has enough time to detect the target before the onset of the mask. Our model deals only with how the combination of the target and mask interferes with detection of the target, and therefore does not, in this case, apply directly to observer performance for an SOA greater than $40 \mathrm{~ms}$.
The exception to this principle is the target field $=$ $33.5 \mathrm{~cd} \mathrm{~m}^{-2}$ condition, where the strongest brightness reversals occur within the masking annuli. Give a limited view of the target and a pronounced brightness reversal within one of the masking annuli, the observer continues to mislocate the target (Lachter, Durgin, \& Washington, 2000). Again, the model accurately represents observer performance. This leaves only two problematic data points: those for target fields equal to 11.5 and $18.1 \mathrm{~cd} \mathrm{~m}^{-2}$ at $\mathrm{SOA}=30 \mathrm{~ms}$. Both are close to $60 \%$ correct, just above chance. Its our belief that these data points represent a transition between those trials on which an observer is sometimes able to detect the target before the onset of the mask and those on which the target is brightness reversed before the observer has detected it.

We have applied our model to experiments with extreme masking conditions - dark-adapted observers and no adaptation field, a high-luminance mask paired with lowluminance targets, and a spatial 2AFC. Even with the present parameters, however, Experiments 2, 3, and 4 demonstrate that brightness reversals go undetected without a direct comparison. Consequently, the negative values of the contrast function $\delta(\tau)$ would indicate the SOA values at which we would expect chance performance with any task that does not allow the observer to compare the target directly with the nontarget condition.
Fig. 8 Data from Experiment 1. Scaled $\Delta(\tau)$ functions from Equation (8) are plotted for SOA values up to $30 \mathrm{~ms}$. These functions are extended as a dashed curve between SOAs of 30 and $40 \mathrm{~ms}$, representing the transition between visual masking and target readout. The parameter values are given in the Appendix. The error bars represent $95 \%$ confidence intervals
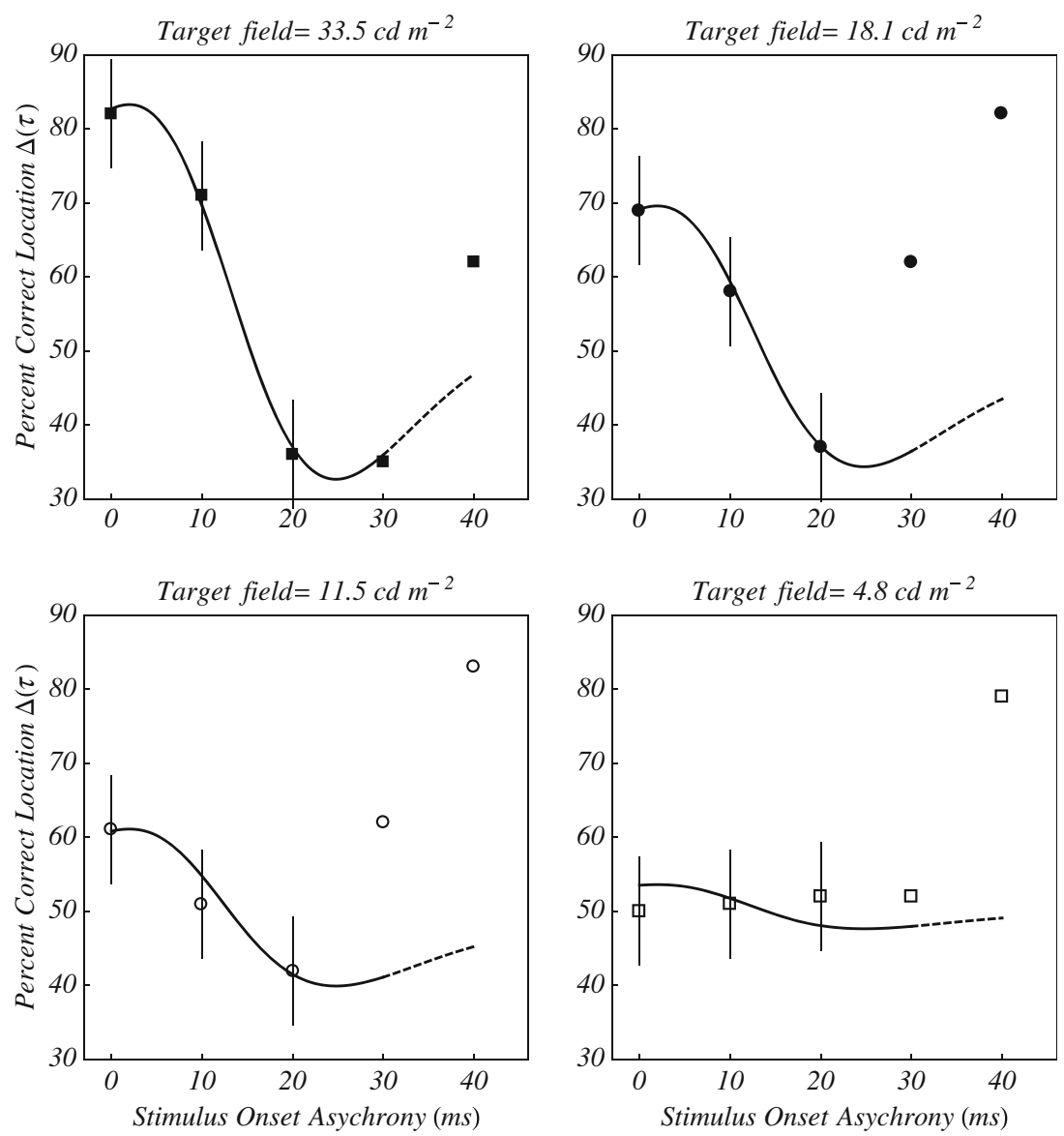


\section{Related ideas}

The impulse is to bypass psychophysics and to leap directly to neurophysiology when modeling visual backward masking. It is tempting to think of the encoded target and mask as readymade agents acting within a particular neural network. We think it is better to err on the side of caution and to concentrate on the psychophysics of visual backward masking (Uttal, 1990, 1997). In modeling backward masking as a secondorder effect, our account of nonmonotone detection curves concerns perception and the behavior of an observer.

Take the problem of understanding an observer's performance when he or she must deal with a brightness reversal. Presented by itself, and followed by a homogeneous masking field, a black target disc can be brightness reversed to be seen as a white disc, possessing both a contour and a bright interior (Breitmeyer et al., 2006). Introducing a black annulus into an otherwise homogeneous masking field has two distinct effects. The first effect of the mask is to incorporate the contour of the target disc within the contour of the inner ring of the mask, leaving an observer with only the brightness within the target and no-target regions as a cue to the target's location. In this respect, the mask turns the observer's task into a brightness judgment analogous to classic metacontrast with a white target surrounded by a white annulus.

The second effect of the black annulus is to confine the action of lateral inhibition to points within the target and nontarget areas (see Purcell, Stewart, \& Dember, 1968). No inhibition is contributed by a completely black masking figure in our model. Rather, it is the inhibition generated within the two illuminated interiors of the two annuli that increases with time and results in a change in brightness analogous to the Broca-Sulzer effect. This accumulation of inhibition renders the brightness of the target indistinguishable from the brightness of the nontarget regions, and in that sense results in visual masking. Also, bear in mind that brightness is not the only quality that changes with this masking paradigm. With black-on-white letters substituted for the black target disc, the percent correct letter identification is also a nonmonotone function of SOA (Stewart \& Purcell, 1970). There is no doubting that a decrease in letter identification also results from masking.

The same mathematical model of masking applies to white-on-black stimuli. Even so, the pattern of excitation and inhibition shifts in our model as figures go from black on white to white on black, with a corresponding change in how we describe the action of lateral inhibition for a particular target and mask. The extreme case is a white figure on a black background. Unlike black-on-white stimuli, where the black figures generate little to no lateral inhibition, both the white mask and the white target figures generate a significant amount of inhibition at points adjacent to their contours, as well as within the white-on- black annulus and white disc themselves. This expression of lateral inhibition is what most models of visual masking deal with, which raises an interesting point. Francis (2000) found that four widely discussed models of masking produce nonmonotone performance functions because the strong target signal blocks the effect of the mask at brief SOAs (Anbar \& Anbar, 1982; Bridgeman, 1977, 1978; Francis, 1997; Weisstein, 1968, 1972). Clearly, the present experiments, with black-on-white masks and targets, do not rely on mask blocking to produce nonmonotone backward masking, distinguishing our account from many of the bestknown explanations of visual backward masking.

While second-order effects can account for nonmonotone performance curves, models of backward masking tell us less about the neurophysiology of visual masking than we desire to know. Take Bridgeman's model of backward masking, for instance (Bridgeman, 1971). His model is an application of the Hartline-Ratliff equation. This equation was devised experimentally to represent recurrent lateral inhibition in the compound eye of Limulus (Ratliff, 1965). As a mathematical entity, the Hartline-Ratliff equation is a special case of our impedance equation. Once the equation is applied to visual masking, however, it is no longer clear whether it represents a single level of processing, as Bridgeman held, or a network of several layers of processing. As we indicate in the Appendix, the solution of the related integral equation is given by a series of terms that alternate in sign (Berman \& Stewart, 1978a, 1978b). The first two terms can be combined to form an impulse function with a positive excitatory lobe and a trailing negative lobe representing inhibition (Watson, 1986). In all, the resolvent kernel of Equation (A4) yields a cascade of five such impulse functions. It is also plausible to think of each term as one of ten successive layers of excitation and feed-forward inhibition (VanRullen, Delorme, \& Thorpe, 2001), or to think of them as the mathematical solution for a single layer of recurrent inhibition, or to think of them as they are: a Neumann series that approximates the solution of a particular integral equation. These are all plausible interpretations of the same mathematical model, with no way to distinguish among them. They are all consistent with the psychophysical evidence. In other words, the underlying physiology is only weakly constrained by the mathematics of Bridgeman's model of backward masking, just as by our model (see also Francis \& Cho, 2008; Macknik, 2006).

We are left with the unhappy conclusion that backward masking and nonmonotone masking curves tell us less about the physiology of the visual system than we would like, although there are compensations. Our mathematical account of second-order effects places backward masking among spatial phenomena such as Mach bands and Westheimer's sensitization effect, and among temporal phenomena such as the Broca-Sulzer effect and visual 
persistence (Berman \& Stewart, 1980; Purcell \& Stewart, 1971; Westheimer, 1967). The model deals with both space and time, and may be useful in areas of experimental and cognitive psychology that employ masking as a tool (Francis, 2007; Francis \& Cho, 2008)-for example, illustrating that briefly presented white-on-black and black-on-white stimuli sometimes produce different results when followed by a visual mask, or making investigators aware that the effectiveness of a mask changes with light adaptation (Purcell \& Stewart, 1975; Purcell, Stewart, \& Stanovich, 1983).

Our approach may also resolve an old dispute. At one time, nonmonotone masking functions were thought to be inconsistent with a luminance-summation account of backward masking (Eriksen, 1966; Eriksen \& Collins, 1964, 1965; Eriksen, Collins, \& Greenspon, 1967; Eriksen \& Marshall, 1969; Purcell \& Stewart, 1975; Schurman \& Eriksen, 1970; Thompson, 1966). Our explanation of the Broca-Sulzer effect maps the solution of our integral equation, which is a function of time, into an intensity function that varies with duration. This mapping sums the net visual response over time, and our account of below-chance chance performance under backward masking is also a product of this mapping. Rather than its being inconsistent with luminance summation, we show that at least one nonmonotone backwardmasking function embodies a form of luminance summation.

\section{Appendix}

The impedance equation

Our model of the Broca-Sulzer effect and second-order visual masking requires that we solve a Fredholm equation of the second kind (Berman \& Stewart, 1978a, 1978b, 1979). The general integral equation is

$r(\boldsymbol{x}, t)=n(\boldsymbol{x}, t)+\int_{0}^{t} \int_{\mathcal{D}} K(\boldsymbol{x}, \boldsymbol{z} ; t, s) n(\boldsymbol{z}, s) d \boldsymbol{z} d s$.

To simplify Equation (A1), assume that the kernel function is a product $K=S T$, with one kernel a function of space and one kernel a function of time. As a concrete example, think of applying this equation to the stimulus and mask of Experiment 1. As we have pointed out, the target disc is not seen as a separate element because its contour is incorporated within the contour of the inner ring of the masking annulus, leaving only the brightness of the target or nontarget area as a cue to the target's presence. For this reason, we are interested only in computing the brightness of the target and nontarget areas. The masking rings enable a further simplification of these computations. Because the black rings isolate their interior discs from the rest of the masking field, we know that the solution of Equation (A1) is almost constant throughout the interior of either region circumscribed by an annulus. The solution is smallest at the center point of each region, and because the center points of the two interior regions represent their smallest respective values, they are directly comparable (Berman \& Stewart, 1980). Consequently, we are interested in the solution of Equation (A1) at only two points in the visual field: the point in the center of region $\mathcal{D}$ (the target-present region) and the point in the center of region $\widetilde{\mathcal{D}}$ (the target-absent region). If inhibition sums over a small spatial region and that region is homogeneous, the spatial contribution of $S$ at a point within $\mathcal{D}$ or $\widetilde{\mathcal{D}}$ will be a constant $c$. Equation (A1) becomes

$r(t)=n(t)+c \int_{0}^{t} T(t, s) n(s) d s$.

Solution of the equation

A simple model of the Broca-Sulzer effect results from solving Equation (A2) when $T$ is a gamma density function given by

$g_{k}(t)=t^{2 k-1} \frac{e^{-t / \sigma_{n e t}}}{\sigma_{n e t}^{2 k} \Gamma(2 k)}$,

where $g=0$ for $t \leq 0$ and $\sigma_{\text {net }}=6.18$ (a summary of all parameters is given in Table 1). Equation (A3) represents $k$ successive convolutions of the exponential density function with itself. For a time-invariant system and an eigenvalue $\lambda$, the resolvent kernel is

$R(t-s)=\sum_{k=0}^{\infty}(-\lambda)^{k} g_{k+1}(t-s)$.

The solution of Equation (A2) at a point $\mathbf{p}$ becomes

$n(t)=r(t)-\lambda c \sum_{k=0}^{\infty}(-\lambda)^{k} \int_{0}^{t} g_{k+1}(t-s) r(s) d s$.

Table 1 Model parameter values

\begin{tabular}{lllll}
\hline Target $\left(\mathrm{cd} \mathrm{m}^{-2}\right)$ & Field $\left(\mathrm{cd} \mathrm{m}^{-2}\right)$ & $M$ & $m$ & Kernel $\sigma$ \\
\hline 0.22 & 4.8 & 200 & 50 & $\sigma_{r}=4.94$ \\
0.54 & 11.5 & 300 & 48.5 & $\sigma_{\text {net }}=6.18$ \\
0.89 & 18.1 & 320 & 49 & $\sigma_{w}=6.25$ \\
2.00 & 33.5 & 255 & 55 & \\
\hline
\end{tabular}

The eigenvalue $\lambda$ and the surround contribution parameter $c$ were fixed for all calculations. The kernel $\sigma$ was used both to compute the Broca-Sulzer functions of Fig. 3 and the masking curves of Fig. 8. Mask $=127.3 \mathrm{~cd} \mathrm{~m}^{-2}$, and eigenvalue $\lambda=0.9$ for all computations. Surround contribution $c=1.6$ for all computations 
In computing the Broca-Sulzer curves of Fig. 3, as well as all other computations, we set the eigenvalue $\lambda=0.9$ and the contribution from the small surround area $c=1.6$. All computations used only the first ten terms of Equation (A5), including the Broca-Sulzer curves of Fig. 3. Additional terms made a negligible contribution.

\section{Computing the visual contrast function}

We now turn to the contrast functions of Fig. 7. For a duration $\tau$, computing the visual contrast $\delta(\tau)$ requires that we know $B(\tau)$ for two points, one in $\mathcal{D}$ and one in $\mathcal{D}$. We illustrate computing $B(\tau)$ for a point centered in $\widetilde{\mathcal{D}}$ with $\mathrm{SOA}=20 \mathrm{~ms}$, target and mask durations of $20 \mathrm{~ms}$, target luminance $=33.5 \mathrm{~cd} \mathrm{~m}^{-2}$, and mask luminance $=$ $127.3 \mathrm{~cd} \mathrm{~m}^{-2}$. The target and mask sequence is represented by the dashed curve in Fig. 9.

Excitation The target and mask sequence is taken as the stimulus $f(t)$. The excitatory response $r(t)$ results from
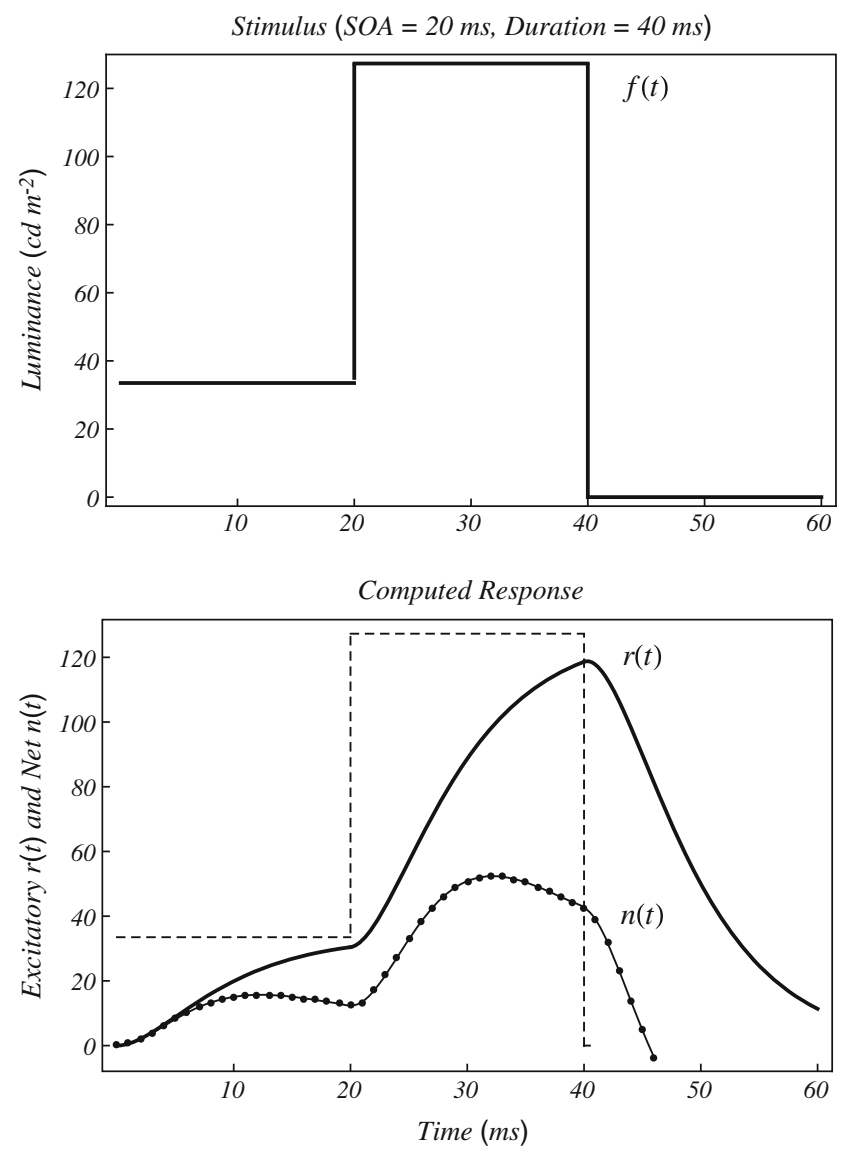

Fig. 9 The top figure is a timing diagram for a stimulus $f(t)$ at a point within the target-absent area $\widetilde{\mathcal{D}}$ and for a single SOA. The response to the stimulus $f(t)$ is shown in the bottom figure as the solid curve labeled $r(t)$. The net response $n(t)$ is plotted as a series of connected points and illustrates how $r(t)$ is modified by inhibition convolving $f(t)$ with the Gamma kernel $g$ of Equation (1). The response $r(t)$ is plotted as the bold solid curve in Fig. 9.

Net output Given the excitatory response $r(t)$, the net output $n$ is computed using Equation (A5). The function $n$ in Fig. 9 is computed in steps of $1 \mathrm{~ms}$, and the resulting values are plotted as a series of points. An interpolation function gives $n$ as a function of time, $n(t)$.

Brightness $B(\tau)$ is computed numerically using Equation (7) for durations of $0-80 \mathrm{~ms}$ in 1-ms steps, and then approximated by an interpolated function. As an example of a one such computation, $B$ for a duration of $40 \mathrm{~ms}$ is

$B(40)=\int_{0}^{\tau=40} n(t) g(40-t) d t$,

for the kernel in Equation (1), $k=2$, and $\sigma=\sigma_{w}=6.25$.

Figure 10 shows two interpolation functions: $B(\tau)$ for a point in $\mathcal{D}$ (the dashed curve) and $B(\tau)$ for a point in $\mathcal{D}$ (the solid curve). The shapes of these two functions are typical of all $B(\tau)$ : Their maximum is at $\mathrm{SOA}=0$, and their minimum is somewhere around $25 \mathrm{~ms}$. At $\mathrm{SOA}=0$, the target region $\mathcal{D}$ has a luminance equal to the black target disc plus the luminance of the mask. The nontarget area $\mathcal{D}$ has a luminance equal to the target field plus the luminance of the mask and appears brighter than the

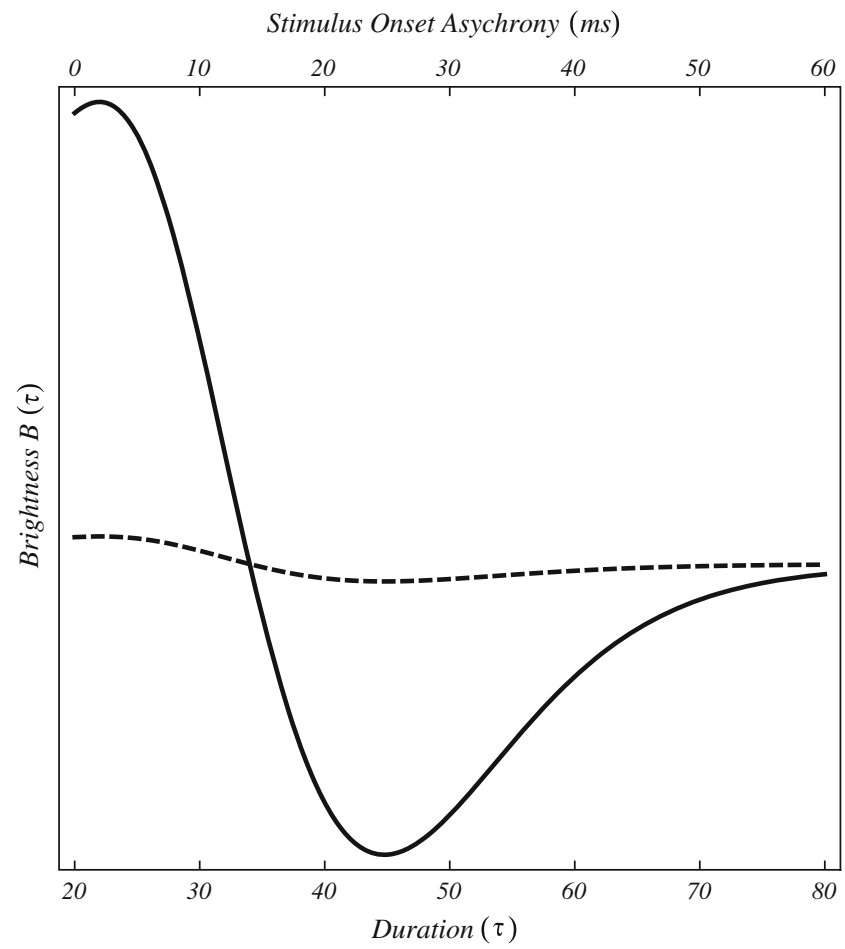

Fig. 10 The dashed curve represents brightness for the target area $D$, and the solid curve represents brightness for the nontarget area $\mathcal{D}$ 
target field, with the result that the black target is easily detected. With increases in SOA, and the resulting increase in inhibition, $B(\tau)$ decreases for both target and nontarget areas. Inhibition is greatest for the nontarget area because it is the area of highest overall luminance. The SOA where the two brightness curves cross represents the second state of visual masking, with $\mathcal{D}$ and $\widetilde{\mathcal{D}}$ equally bright. Further decreases in $B(\tau)$ for $\tilde{\mathcal{D}}$ cause the target region $\mathcal{D}$ to appear brighter than $\mathcal{D}$. Presumably, if an observer is looking for a black target, he or she would mistake $\mathcal{D}$ for the target region.

Figure 10 also clarifies how brightness reversals originate. A moment's reflection reveals that the luminance profile of the nontarget area is the same as that of the target field surrounding the black target disc. For the target and mask fields, for all SOAs, the brightness of the target's surrounding visual field must be similar to that of the solid curve of Fig. 10. Therefore, even though the brightnesses of the target and of its surround both decrease with increases in SOA, the brightness of the target is greater than the brightness of its visual surround from $\mathrm{SOA}=14$ to $60 \mathrm{~ms}$. That is, the target is brightness reversed.

The function $\delta(\tau)$ The two brightness functions $B(\tau)$ of Fig. 10, combined according to Equation (8), produce the topmost $\delta(\tau)$ function of Fig. 7.

\section{References}

Anbar, S., \& Anbar, D. (1982). Visual masking: A unified approach. Perception, 11, 427-439.

Berman, S. M., \& Stewart, A. L. (1978a). Laterally induced impedance effects in vision. Journal of Mathematical Psychology, 18, 73-99. doi:10.1016/0022-2496(78)90049-4

Berman, S. M., \& Stewart, A. L. (1978b). The mathematical theory of lateral impedance of visual activity and an application of Markov processes. Biological Cybernetics, 30, 99-108.

Berman, S. M., \& Stewart, A. L. (1979). A unified model for the combined temporal and spatial Broca-Sulzer effect. Biological Cybernetics, 34, 171-179.

Berman, S. M., \& Stewart, A. L. (1980). Application of ordered topological vector spaces in the modeling of visual difference thresholds. Mathematical Biosciences, 50, 133-154.

Bernstein, I. H., Proctor, J. D., Proctor, R. W., \& Schurman, D. L. (1973). Metacontrast and brightness discrimination. Perception \& Psychophysics, 14, 293-297. doi:10.3758/ BF03212393

Blanc-Garin, J. (1969). L'interaction spatio-temporelle des données de la perception visuelle. Unpublished doctoral dissertation, University of Paris, France.

Bowen, R. W. (1984). Temporal brightness enhancement: Studies of individual differences. Perception \& Psychophysics, 36, 401-408.

Boynton, R. M. (1961). Some temporal factors in vision. In W. A. Rosenblith (Ed.), Sensory communication (pp. 739-756). Cambridge, MA: MIT Press.
Breitmeyer, B. G. (1984). Visual masking: An integrative approach. New York: Oxford University Press.

Breitmeyer, B. G., Kafaligönül, H., Öğmen, H., Mardon, L., Todd, S., \& Ziegler, R. (2006). Meta- and paracontrast reveal differences between contour- and brightness-processing mechanisms. Vision Research, 46, 2645-2658. doi:10.1016/j. visres.2005.10.020

Breitmeyer, B. G., \& Öğmen, H. (2000). Recent models and findings in visual backward masking: A comparison, review, and update. Perception \& Psychophysics, 62, 1572-1595.

Breitmeyer, B. G., \& Öğmen, H. (2006). Visual masking: Time slices through conscious and unconscious vision (2nd ed.). New York: Oxford University Press.

Bridgeman, B. (1971). Metacontrast and lateral inhibition. Psychological Review, 78, 528-539.

Bridgeman, B. (1977). A correlational model applied to metacontrast: Reply to Weisstein, Ozog, and Szoc. Bulletin of the Psychonomic Society, 10, 85-88.

Bridgeman, B. (1978). Distributed sensory coding applied to simulations of iconic storage and metacontrast. Bulletin of Mathematical Biology, 40, 605-623.

Broca, A., \& Sulzer, D. (1902). La sensation lumineuse en fonction du temps. Journal de Physiologie et de Pathologie Générale, 4, $632-640$.

Brussell, E. M., Stober, S. R., \& Favreau, O. E. (1978). Contrast reversal in backward masking. Vision Research, 18, 225-227.

Corwin, T. R. (1978). The effect of retinal eccentricity on the BrocaSulzer phenomenon. Vision Research, 18, 865-867. doi:10.1016/ 0042-6989(78)90131-1

Dorfman, D. D., \& Alf, E., Jr. (1969). Maximum-likelihood estimation of parameters of signal-detection theory and determination of confidence intervals - Rating-method data. Journal of Mathematical Psychology, 6, 487-496. doi:10.1016/0022-2496(69) 90019-4

Eriksen, C. W. (1966). Temporal luminance summation effects in backward and forward masking. Perception \& Psychophysics, 1 , 87-92.

Eriksen, C. W., \& Collins, J. F. (1964). Backward masking in vision. Psychonomic Science, 1, 101-102.

Eriksen, C. W., \& Collins, J. F. (1965). Reinterpretation of one form of backward and forward masking in visual perception. Journal of Experimental Psychology, 70, 343-351. doi:10.1037/ h0022196

Eriksen, C. W., Collins, J. F., \& Greenspon, T. S. (1967). An analysis of certain factors responsible for non-monotonic backward masking functions. Journal of Experimental Psychology, 75, 500-507.

Eriksen, C. W., \& Marshall, P. H. (1969). Failure to replicate a reported U-shaped visual masking function. Psychonomic Science, 15, 195-196.

Francis, G. (1997). Cortical dynamics of lateral inhibition: Metacontrast masking. Psychological Review, 104, 572-594. doi:10.1037/ 0033-295X.104.3.572

Francis, G. (2000). Quantitative theories of metacontrast masking. Psychological Review, 107, 768-785. doi:10.1037/0033295X.107.4.768

Francis, G. (2003). Developing a new quantitative account of backward masking. Cognitive Psychology, 46, 198-226. doi:10.1016/S0010-0285(02)00521-2

Francis, G. (2007). What should a quantitative model of masking look like and why would we want it? Advances in Cognitive Psychology, 3, 21-31. doi:10.2478/v10053-008-0011-6

Francis, G., \& Cho, Y. S. (2008). Effects of temporal integration on the shape of visual backward masking functions. Journal of Experimental Psychology: Human Perception and Performance, $34,1116-1128$. 
Heckenmuller, E. G., \& Dember, W. N. (1965). Paradoxical brightening of a masked black disc. Psychonomic Science, 3, 457-458.

Higgins, K. E., \& Rinalducci, E. J. (1975). Suprathreshold intensityarea relationships: A spatial Broca-Sulzer effect. Vision Research, 15, 129-143.

Hogben, J. H., \& Di Lollo, V. (1984). Practice reduces suppression in metacontrast and in apparent motion. Perception \& Psychophysics, $35,441-445$.

Jarmasz, J., \& Hollands, J. G. (2009). Confidence intervals in repeated measures designs: The number of observations principle. Canadian Journal of Experimental Psychology, 63, 124-138.

Lachter, J., Durgin, F., \& Washington, T. (2000). Disappearing percepts. Evidence for retention failure in metacontrast masking. Visual Cognition, 7, 269-279.

Macknik, S. L. (2006). Visual masking approaches to visual awareness. In S. Martinez-Conde, S. L. Macknik, L. M. Martinez, J.-M. Alonso, \& P. U. Tse (Eds.), Visual perception: Part 2. Fundamentals of awareness: Multi-sensory integration and high-order perception (Progress in Brain Research, Vol. 155, pp. 177-215). Amsterdam: Elsevier.

Macmillan, N. A., \& Creelman, C. D. (2005). Detection theory: A user's guide (2nd ed.). Mahwah, NJ: Erlbaum.

Marks, L. E. (1974). Chapter 4. Temporal factors in sensation. In L. E. Marks, Sensory processes: The new psychophysics (pp. 99-106). New York: Academic Press.

Osaka, N. (1982). Exponent for the Broca-Sulzer flash duration as a function of retinal eccentricity. Journal of the Optical Society of America, 72, 62-67.

Purcell, D. G., \& Dember, W. N. (1968). The relation of phenomenal brightness reversal and re-reversal to backward masking and recovery. Perception \& Psychophysics, 3, 290-292. doi:10.3758/ BF03212748

Purcell, D. G., \& Stewart, A. L. (1969). Facilitation of visual backward masking by increasing target duration: A methodological extension. Psychonomic Science, 17, 360-361.

Purcell, D. G., \& Stewart, A. L. (1970). U-shaped backward masking functions with nonmetacontrast paradigms. Psychonomic Science, 21, 361-363.

Purcell, D. G., \& Stewart, A. L. (1971). The two-flash threshold: An evaluation of the critical-duration and visual-persistence hypotheses. Perception \& Psychophysics, 9, 61-64.

Purcell, D. G., \& Stewart, A. L. (1974). Backward masking by pattern mask: Effect of adaptation and target energy. Bulletin of the Psychonomic Society, 3, 137-138.

Purcell, D. G., \& Stewart, A. L. (1975). A comparison of white and black targets under conditions of masking by a patterned stimulus. Bulletin of the Psychonomic Society, 6 , $13-15$.

Purcell, D. G., \& Stewart, A. L. (1988). The face-detection effect: Configuration enhances detection. Perception \& Psychophysics, 43, 355-366. doi:10.3758/BF03208806

Purcell, D. G., \& Stewart, A. L. (1991). The object-detection effect: Configuration enhances perception. Perception \& Psychophysics, 50, 215-224. doi:10.3758/BF03206744

Purcell, D. G., Stewart, A. L., \& Dember, W. N. (1968). Spatial effectiveness of the mask: Lateral inhibition in visual backward masking. Perception \& Psychophysics, 4, 344-346. doi:10.3758/ BF03209530

Purcell, D. G., Stewart, A. L., \& Dember, W. N. (1969). Backward masking: Facilitation through increased target-field luminance and duration. Psychonomic Science, 15, 87-88.

Purcell, D. G., Stewart, A. L., \& Stanovich, K. E. (1983). Another look at semantic priming without awareness. Perception \& Psychophysics, 34, 65-71.
Ratliff, F. (1965). Mach bands: Quantitative studies on neural networks in the retina. New York: Holden-Day.

Rolls, E. T., Tovée, M. J., Purcell, D. G., Stewart, A. L., \& Azzopardi, P. (1994). The responses of neurons in the temporal cortex of primates and face identification and detection. Experimental Brain Research, 101, 473-484.

Schurman, D. L., \& Eriksen, C. W. (1970). Summation and interaction of successive masking stimuli in visual perception. American Journal of Psychology, 82, 320-332.

Schwiedrzik, C. M., Singer, W., \& Melloni, L. (2009). Sensitivity and perceptual awareness increase with practice in metacontrast masking. Journal of Vision, 9(10), 18:1-18.

Stewart, A. L., Pinkham, R. S., Bittner, T. K., \& Purcell, D. G. (2003). Hermite acuity gratings and models of space-variant acuity. Vision Research, 43, 1597-1610.

Stewart, A. L., Pinkham, R. S., Mancino, P. A., \& Chomak, J. M. (1999). Representing contrast detection as an eigenvalue problem. Spatial Vision, 12, 397-419.

Stewart, A. L., \& Purcell, D. G. (1970). U-shaped masking functions in visual backward masking: Effects of target configuration and retinal position. Perception \& Psychophysics, 7, 253-256. doi:10.3758/BF03209373

Stewart, A. L., Purcell, D. G., \& Dember, W. N. (1968). Masking and recovery of target brightness. Proceedings of the Annual Convention of the American Psychological Association, 3, 109-110.

Thompson, J. H. (1966). What happens to the stimulus in backward masking? Journal of Experimental Psychology, 71, 580-586. doi: $10.1037 / \mathrm{h} 0022957$

Uttal, W. R. (1990). On some two-way barriers between models and mechanisms. Perception \& Psychophysics, 48, 188-203. doi: $10.3758 / \mathrm{BF} 03207086$

Uttal, W. R. (1997). Toward a new behaviorism: The case against perceptual reductionism. Mahwah, NJ: Erlbaum.

VanRullen, R., Delorme, A., \& Thorpe, S. J. (2001). Feed-forward contour integration in primary visual cortex based on asynchronous spike propagation. Neurocomputing, 38, 10031009.

Ventura, J. (1980). Foveal metacontrast: I. Criterion content and practice effects. Journal of Experimental Psychology: Human Perception and Performance, 6, 473-485.

Waldmann, M. R., \& Göttert, R. (1989). Response bias in belowchance performance: Computation of the parametric measure $\beta$. Psychological Bulletin, 106, 338-340. doi:10.1037/00332909.106.2.338

Wasserman, G. S., \& Kong, K.-L. (1974). Illusory correlations of brightness enhancement and transients in the nervous system. Science, 184, 911-913. doi:10.1126/science.184.4139.911

Watson, A. B. (1986). Chapter 6. Temporal sensitivity. In K. R. Boff, L. Kaufman, \& J. P. Thomas (Eds.), Handbook of perception and human performance: Vol. I. Sensory processes and perception. New York: Wiley.

Weisstein, N. (1968). A Rashevsky-Landahal neural net: Simulation of metacontrast. Psychological Review, 75, 494-521.

Weisstein, N. (1972). Metacontrast. In D. Jameson \& L. Hurvich (Eds.), Handbook of sensory physiology: Vol. 7. Visual psychophysics. Berlin: Springer.

Weisstein, N., \& Haber, R. N. (1965). A U-shaped backward masking function in vision. Psychonomic Science, 2, 75-76.

Weisstein, N., Ozog, G., \& Szoc, R. (1975). A comparison and elaboration of two models of metacontrast. Psychology Review, 82, 325-343. doi:10.1037/0033-295X.82.5.325

Westheimer, G. (1967). Spatial interaction in human cone vision. Journal of Physiology, 181, 139-154.

Wolford, G., Marchak, F., \& Hughes, H. (1988). Practice effects in backward masking. Journal of Experimental Psychology: Human Perception and Performance, 14, 101-112. 